\title{
Editorials
}

\section{Challenges to public health in the new millennium}

Of all the medical specialties, it is public health that by its very nature is most affected by political, social and economic changes. Therefore the challenge to public health in the new millennium will be deciding how to adapt to the simultaneous changes in all these areas created by the forces of globalisation. Diseases will travel faster than every before, as will the information (and misleading pseudo-information) abut how to treat them. Information and mobility will bring great wealth to some and the troubles of the very poor, especially their health problems, closer to all of us. Existing political power structures will be challenged by the power of big business and, perhaps, small organisations, ranging from legitimate and well meaning pressure groups to terrorist organisations, newly empowered by modern information technology. International organisations such as the European Union, will develop as an attempt by nation states to rescue their power by sharing it.

The last great paradigm shift in social development was the industrial revolution of the 19th century. The transformation of an agrarian, socially stable society with little political or physical mobility into an urban society on the move in every sense, which was most noticeable in the United Kingdom but was mirrored throughout much of the world, shares many parallels with the impact globalisation will have. Back then the UK's 1848 Public Health Act and its successors were the finest examples anywhere of public health helping to shape a social transformation in a humane direction. The UK can once again take a lead in this by asking "do we need a Health of the People Bill?" Despite the gathering pace of globalisation, nation states still for the moment have the capacity for meaningful action and leadership.

The approach to public health established by the 1848 Act, as well as by other Acts introduced in the last century, certainly led to dramatic improvements in the health of the people. These Acts have continued to be effective in both preserving and promoting health even though there have been major changes in the structure of central and local government, the introduction of an NHS and the privatisation of such fundamental public health provisions as water supply and sewerage. But with devolution, European law and changes in disease occurrence and demography, the laws governing public health need updating and tidying up. In a democracy it is actually important to know who is responsible for what. No one should be able to avoid blame and no one should be required to accept blame for matters that are beyond their control. We have come close to that on recent occasions.

The determinants of health have, on the whole, little to do with the health service, and public health has been overmedicalised in many countries. Local authorities in particular play a crucial part. The assessment of the lessons from The Health of the Nation are that local authorities were undervalued and marginalised and it is clear that these lessons have been learned by the present government. A positive health approach with local strategies, locally owned, offers a way of getting local government and local people more actively engaged in a public health agenda.

To improve and maintain health requires international and national coordination because the factors that influence health know no boundaries and although the needs of different areas, for example, urban and rural, will vary, central coordination and leadership is crucial

Furthermore, devolution in the United Kingdom-a feature of many other countries - has led to the establishment of a Scottish Parliament and a Welsh Assembly with significant devolved law making powers and in Scotland "including overall responsibility for the NHS in Scotland and public and mental health". Beef on the bone has already been raised as early business in the Assembly and the Parliament and different practices may be adopted on either side of the English borders. These developments have important public health implications, and Canada and Australia-countries with a federal structure-can provide examples of how to tackle the problems that will certainly arise.

In his Annual Report for 1998 the CMO for England said "The 1848 Act had a Board of Health, a high-level committee to oversee the changes proposed. Perhaps something similar would be useful now". Perhaps it would. Those attending the Nuffield Trust Christ Church workshop in July 1998 certainly thought so.

In the United Kingdom it may also be necessary to strengthen the role of ministers-especially that of the Secretary of State for Health-in relation to those matters for which they do have direct responsibility, such as international negotiation and maintaining a broad policy overview. It is their job to ensure, whether through legislation or otherwise, that the responsibilities of the key players are clearly defined and to satisfy themselves that effective structures are in place for improving the health of the people. The Secretary of State, as the public health minister in the United Kingdom cabinet, will need clarity about their role and that of ministers responsible for public health in the nations of the United Kingdom. A high level advisory council of experts and representatives of countries and regions is needed to provide the necessary authoritative advice to the Secretary of State so that he is able to give the necessary leadership. This Council must have the ability both to devise and collect the appropriate information that is crucial for the execution of policies. It must also have the power to publish and disseminate information, which may be uncomfortable for ministers, to influence public knowledge and behaviour. Recent concerns about, for example, BSE and genetically modified foods demonstrate the need for ministers to have access to public health experts and for the public to be reassured that the advice they receive is sound and independent. None of this is new and much of what we advocate returns us to the position that public health had at the end of the last century.

It is also important to distance ministers from certain matters, such as the collection and dissemination of information and statistics about the health of the people and the factors that affect it. An independent body - a commission or board acting as the champion for the health of the public and operating at arm's length from central and local government - could do much to meet those two needs, and strengthen public confidence in the public health function.

The European Union has now firmly put its badge on public health as a subject but there is a lack of overall coordination of public health across the different directorates of 
the Commission. We also need to sort out how institutions such as the WHO European Regional Office, which possesses significant resources and expertise, can be harnessed successfully to the benefit of Europe as a whole and in a way that would be both helpful and effective. If in the next few years the United Kingdom successfully develops its own public health function, achieving the right bal- ance of harmonisation and subsidiarity in the context of Europe, devolution and the renewal of local government, it would be well placed to take the initiative and provide a lead on public health in Europe as well.

JOHN WYN OWEN CB

\section{Drinking water and gastrointestinal disease: need of better understanding and an improvement in public health surveillance}

Twenty five per cent of the population in the developing world have no access to drinking water. Infectious and parasitic diseases are still the principal cause of death and illness throughout the world, mostly because of the poor quality of water, and diarrhoea ranked globally in 1997 as the first cause of morbidity and the sixth cause of mortality. ${ }^{1}$ The actual burden of waterborne diseases is unknown because of underreporting in both developed and developing countries. ${ }^{2}$ A recently published work shows that infectious intestinal disease occurs in one in five people each year in England, but only a small proportion of cases are recorded by national laboratory surveillance system. ${ }^{3}$ In communities with a high economic and public health development access to abundant and good quality water is stated as a basic right, and consumption of tap water is not seen as an important risk. Otherwise, in recent years some concern has been raised about the safety of drinking water, both in Europe and North America. On one hand, in some regions of Europe, specially those in the former Soviet Union, there is evidence of increase in disease attributable to restricted water supply. ${ }^{4}$ Apart from that, the privatisation of water supplies in some countries (for example, UK), and its subsequent price increase, could lead to a reduction of its use for low income groups introducing potential detriment of their health. ${ }^{5}$ In addition, chemical products in drinking water have been associated with bladder and pancreatic cancer, ${ }^{6-8}$ and also with reproductive effects. ${ }^{9-11}$

In countries with good epidemiological surveillance systems, a series of waterborne outbreaks have been reported in communities with adequate established measures of water quality control. This represents a warning about the potential risks from drinking water despite the state of the art water treatment. ${ }^{5912}$ One of the best known outbreaks happened in Milwaukee (Wisconsin). In March of 1993, and because of a contaminated water supply, there was a widespread outbreak of gastrointestinal illnesses, mainly attributable to Cryptosporidium among the residents of Milwaukee that affected more than 400000 people (about 30 per cent of the population). ${ }^{13}$ Before this outbreak there were marked increases in the turbidity of treated water, reaching a maximal daily turbidity of 1.7 nephelometric turbidity units (NTU). After this episode the standards for water treatment were proposed to be strengthened in the United States $(95 \%$ of all daily finished water turbidity measurements in a month should not exceed 0.5 NTU). Likewise, two randomised controlled intervention trials conducted in Quebec, found that $14 \%$ to $40 \%$ of gastroenteritis were associated with tap water ${ }^{14}{ }^{15}$ suggesting the importance of drinking water in occurrence of endemic gastrointestinal disease.
Attention paid to health problems regarding drinking water is in a considerable amount attributable to the gastrointestinal disease incidence related with pathogens that are not easy to control - that is, they are difficult to detect and to eliminate from water using conventional procedures, such as viruses (for example, Norwalk virus, ${ }^{16}$ hepatitis A virus or rotavirus ${ }^{2}$ ), and parasites. In the 1980 s Giardia was considered as the most frequently isolated enteric protozoan from populations worldwide and the most common pathogenic parasitic in the United States. ${ }^{17}$ Otherwise, nowadays, the deepest concern comes from the potential health risks associated with waterborne cryptosporidiosis. ${ }^{18}$ The major difficulties dealing with Cryptosporidium are that it is difficult to detect in water samples, it is very resistant to disinfection, its infective dose is low, it could affect more severely immunocompromised subpopulations, and, at present, there seems to be no effective treatment. ${ }^{1920}$

In this issue of the journal, Schwartz and colleagues present a time series study examining the relation between daily fluctuations in drinking water turbidity and hospital admissions for gastrointestinal disease of elderly people in Philadelphia. ${ }^{21}$ Regarding population aged 65 and older, they found that an interquartile range increase in tap water turbidity was associated with a 9\% increase (95\% confidence intervals $5.3 \%, 12.3 \%$ ) in hospital admissions, 9 to 11 days after. The association was stronger in those over 75 than in people aged $65-74$.

$\mathrm{Up}$ to now, most of epidemiological studies of waterborne diseases are investigations of severe outbreaks. With this approach a limited period of time in which a number of cases higher than expected occurred is examined. Subsequently confirmed cases are described regarding personal characteristics and exposure to water, and comparisons with controls are made. In the past years, however, and the article from Schwartz and colleagues presented here is a good example, another approach is being used. This relies on assessment of the relation between daily variations of health and water indicators using time series techniques. ${ }^{21-24}$ Time series analysis measured the short-term associations between an effect indicator (that is, hospital admissions for gastrointestinal disease) and an exposure (that is, water turbidity). This approach has been successfully developed for the study of the health effects of air pollution on daily hospital admissions and mortality. The underlying hypothesis is that part of the variance of the usual (that is, nonepidemic) daily distribution of the health effect is associated with the daily fluctuations of the exposure indicator, after considering all the potential confounding factors, using Poisson regression techniques. The main 
advantage of this design is that the population under study serves as its own control, and covariates that vary between subjects but not over time are not potential confounders. In addition, covariates that vary across people tend to remain constant over time or their daily variations are unlikely to change with the exposure of interest. ${ }^{232526}$ Another advantage of these designs seeking at short-term effects is that the potential biases are reduced to the factors changing day to day and related to both water and health effect indicators. The main limitations of these studies in providing strong evidence derive from their ecological design. ${ }^{27}$ Thus, the measurement of exposure is a daily average for the city, the correlation of which with the personal exposure depends on individual patterns of water drinking, such as the amount of water consumed. In a recent paper ${ }^{28}$ Schwartz and Levin, answering some criticisms after another article on this topic, ${ }^{23}$ argued that most of the misclassification error in exposure was non-differential, and the estimated effect resulted biased downward. Besides, they demonstrated that misclassification of disease cannot bias the estimated effect unless misdiagnosis of disease would have to vary daily in correlation with turbidity.

These two articles in Philadelphia, ${ }^{21}{ }^{23}$ contribute, in our opinion, with two principal features. Firstly, from an epidemiological point of view, they deal with endemic rather than epidemic presentation of disease. And, secondly, from the public health point of view, the association occurred in filtered water supply accomplishing the current US standards. It is important to note that the first evidences suggesting the possibility that air pollutants could have a significant impact on health at levels around or below the established standards came from time trends studies, which has been further confirmed by other type of studies. The merit of Schwartz and colleagues has been to show non-detected associations between environmental factors (that is, yesterday air pollution, today water pollution) and health indicators in the ecological domain, with a strong potential for prevention. To improve the knowledge about endemic waterborne disease, the use of other surrogate measures of microbial contamination of drinking water in addition to turbidity has been claimed, ${ }^{29}$ as well as a search of the impact of its variations on general population rather than focusing only on people demanding hospital attention. ${ }^{29} 30$

In Europe, to date, no reliable data are available to estimate the burden of water related diseases and waterborne disease outbreaks. In 1997, the WHO for Europe asked 52 European countries for information on health effects related to contaminants in water for the period 1986-1996..$^{5}$ Only 26 countries returned the questionnaires. Furthermore, not all these countries provided data on waterborne diseases or outbreaks. Most countries reported less cases of gastrointestinal diseases linked to drinking water than cases of such diseases reportedly associated with outbreaks. For example, Spain did not provide data about the gastrointestinal disease incidence, however it was the country with the highest number of reported waterborne outbreaks $(n=208)$.

The understanding of the actual impact of drinking water quality on human diseases will be difficult to reach. On the one hand, to establish solely stricter water treatment guidelines could not ensure a tap water completely free of risks. On the other hand, a passive surveillance system has serious limitations to detect endemic gastrointestinal disease, and even mild or moderate outbreaks. It could be more convenient to combine monitoring water quality and epidemiological surveillance. ${ }^{31}{ }^{33} \mathrm{~A}$ comprehensive public health surveillance strategy seems the most efficient approach to better understand and control the impact of water quality on gastrointestinal disease.
The proposals for Cryptosporidium surveillance ${ }^{18} 19$ could be extended to other gastrointestinal diseases, including: increase of surveillance for cases of diarrhoea and/or vomiting, especially of populations at risk; standardisation of laboratory detection; designation of specific gastrointestinal illnesses as reportable diseases; and an accurate investigation and control of waterborne outbreaks. Seroepidemiological studies have also been proposed as an alternative to improve estimates of the extent of endemic waterborne transmission for many aetiological agents. ${ }^{33} 34$ The use of time series techniques in surveillance has been recommended..$^{31}$ However, the use of more specific indicators of water contamination are required to improve the surveillance methods of "safe" drinking water contamination in gastrointestinal infections in the developed world. Because of the fact that many pathogens could have a potential role in waterborne diseases it is important to investigate developing methods that can simultaneously measure the presence of many pathogens. In this sense, the use of DNA chip technology ${ }^{35}$ could represent a good chance to detect the presence of multiple pathogens in drinking water. Regarding the potential benefits of surveillance, an analysis of the Milwaukee cryptosporidiosis outbreak using dynamic modelling suggested that, had surveillance systems detected the earlier outbreak, up to $85 \%$ of the cases might have been prevented. ${ }^{36}$

Besides surveillance, two more needs have been stated as crucial for the future microbiological safety of drinking water, integration of risk assessment methodologies, and the understanding of the pathogen's ecology. ${ }^{217}{ }^{20}$ Regarding the understanding of the aetiological processes, evidences from time series studies, as in the field of the study of air pollution effects, must be complemented by studies on sensitive people and on pathogenic mechanisms of microorganisms. Furthermore, a more proactive role of public health professionals has been demanded ${ }^{20}$ encourag- $^{-}$ ing the promotion of a communication programme with physicians and other sanitarian professionals, and contributing to the development of public health policies that limit contamination of source water, improve water treatment and protect public health. Lastly, but not least, drinking water industry and the public must be informed and invited to participate in the design and goals of the new disease surveillance and public health programmes.

FERRAN BALLESTER

Epidemiology and Statistics Unit, Institut Valencià d'Estudis en Salut Pública, ClFoan de Garay, 21 46017, Valencia, Spain

JORDI SUNYER

Respiratory and Environmental Reserach Unit, Institut Municipal d'Investigació Mèdica de Barcelona, Spain

Correspondence to: Dr Ballester.

1 World Health Organization (WHO). The World Health Report 1998. Life in the 21 st century. $A$ vision for all. Geneva: WHO, 1998.

2 Ford T. Microbial safety of drinking water: United States and global perpspectives. Environ Health Perspect 1999;107 (suppl 1):191-206.

3 Wheeler J, Sethi D, Cowden J, et al. Study of infectious intestinal disease in England: rates in the community, presenting to general practice, and England: rates in the community, presenting to genera
reported to national surveillance. $B M \not \mathcal{1} 1999 ; 318: 1046-50$.

4 World Health Organization (WHO). Epidemiological aspects of investigation of outbreaks of communicable diseases and surveillance and control of water quality. Report 02427. Target 20. Copenhagen: WHO, 1997.

5 ETCIW. Under contract to the European Environment Agency and World Health Organization (WHO). Water resources and human health in Europe. Environmental issues serie (DRAFT). Available from http://www.who.dk/ London99/WelcomeE.htm

6 Ward M, Mark S, Cantor K, et al. Drinking water nitrate and the risk of non-hodgkin's lymphoma. Epidemiology 1995;7:465-71.

7 World Health Organization (WHO). Guidelines for drinking-water quality. 2nd ed. Geneva: WHO, 1996.

8 Boorman G, Dellarco V, Dunnick J, et al. Drinking water disinfection byproducts: review an approach to toxicity evaluation. Environ Health Perspect 1999;107 (suppl 1):207-17.

9 Kramer MH, Herwaldt BL, Craun GF, et al. Surveillance for waterborneKramer MH, Herwaldt BL, Craun GF, et al. Surveillance for waterborne-
disease outbreaks-United States, 1993-1994. Morb Mortal Wkly Rep 1996; 45:1-33. 
10 Sawan S, Waller K. Disinfection by-products and adverse pregnancy outcomes: what is the agent and how should it be measured? Epidemiology outcomes: what is

11 Gallagher M, Nuckols J, Stallones L, et al. Exposure to trihalomethanes and adverse pregnancy outcomes. Epidemiology 1998;9:484-9.

12 Goldstein S, Juranek DD, Ravenholt O, et al. Crytosporidiosis: an outbreak associated with drinking water despite state-of-the-art water treatment. Ann Intern Med 1996;124:459-68.

13 MacKenzie W, Hoxie N, Proctor M, et al. A massive outbreak in Milwaukee of cryptosporidium infection transmitted through the public water supply. N Engl f Med 1994;331:161-7.

14 Payment P, Siemiatycki J, Richardson L, et al. A prospective epidemiological study of gatrointestinal health effects due to the consumption of drinking water. Int $\mathcal{F}$ Environ Health Research 1997;7:5-31.

15 Payment P, Richardson L, Siemiatycki J, et al. A randomized trial to evaluate the risk of gastrointestinal disease due to consumption of drinking water meeting current microbiological standars. Am f Public Health 1991;81:703-8.

16 Chover J, Pastor S, Roig F, et al. Brote de gastroenteriritis asociado al consumo de agua, posiblemente producido por virus tipo norwalk o sumo de agua, posiblemente producido por

17 Rose J, Haas C, Regli S. Risk assessment and control of waterborne Giardiasis. Am f Public Health 1991;81:709-13. 18 US Departament of Health and Human Services.CDC. Assessing the public health threat associated with waterborne Cryptospo
workshop. Morb Mortal Wkly Rep 1995;44 (RR6):1-19.

19 Meinhardt P, Casemore D, Miller K. Epidemiologic aspects of human Cryptosporidiosis and the role of waterborne transmission. Epidemiol Rev 1996;18:118-36.

20 Rose J. Environmental ecology of cryptosporidium and public health implications. Annu Rev Public Health 1997;18:135-61.

21 Schwartz J, Levin R, Goldstein R. Drinking water turbidity and gastrointestinal illness in the elderly of Philadelphia. F Epidemiol Community Health 2000;54:45-51.

22 Morris RD, Naumova EN, Levin R, et al. Temporal variation in drinking water turbidity and diagnosed gastroenteritis in Milwaukee. Am $\mathcal{F}$ Public Health 1996;86:237-9.
23 Schwartz J, Levin R, Hodge K. Drinking water turbidity and pediatric hospital use for gastrointestinal illness in Philadelphia. Epidemiology 1996;8: $615-20$

24 Morris RD, Naumova EN, Griffiths J. Did Milwaukee experience waterborne cryptosporidiosis before the large documented outbreak in 1993? Epidemiology 1998;9:264-70.

25 Schwartz J, Spix C, Touloumi G, et al. Methodological issues in studies of air pollution and daily counts of deaths or hospital admissions. 7 Epidemiol Community Health 1996;50 (suppl 1:S3-11.

26 Hertz-Picciotto I. Environmental epidemiology. In: Rothman K, Greenland S, eds. Modern epidemiology. Philadelphia: Lippincot-Raven, 1998.

27 Morgensten $\mathrm{H}$. Ecologic studies in epidemiology: concepts, principles, and methods. Anпu Rev Public Health 1995;16:61-81.

28 Schwartz J, Levin R. Drinking water turbidity and health. Epidemiology 1999;10:86-90.

29 Juranek D, Mac Kenzie W. Drinking water turbitity and gastrointestinal illness. Epidemiology 1998;9:228-31.

30 Franco E. Defining safe drinking water. Epidemiology 1997;8:607-9.

31 Quénel P. Surveillance de santé publique et environnement. Rev Epidem et Santé Publ 1995;43:412-22.

32 Hellard M, Sinclair M, Streeton C, et al. Commentary. Driking water and microbiological pathogens-issues and challenges for the year 2000. F Public Health Med 1997;19:129-31.

33 Frost F, Graun G, Calderon RL. Waterborne disease surveillance. Fournal of American Water Works Association 1996;88:66-75.

34 Payment P, Franco E, Fout GS. Incidence of Norwalk virus infections during a prospective epidemiological study of drinking water-related gastrointestinal illness. Can f Microbiol 1994; 40: 805-9.

35 Whitcombe D, Newton CR, Little S. Advances in approaches to DNA-based diagnostics. Curr Opin Biotechnol 1998; 9:602-8.

36 Eisenberg J, Seto E, Colford J, et al. An Analysis of the Milwaukee cryptosporidiosis outbreak based on a dynamic model of the infection process. Epidemiology 1997;9:255-63. 